
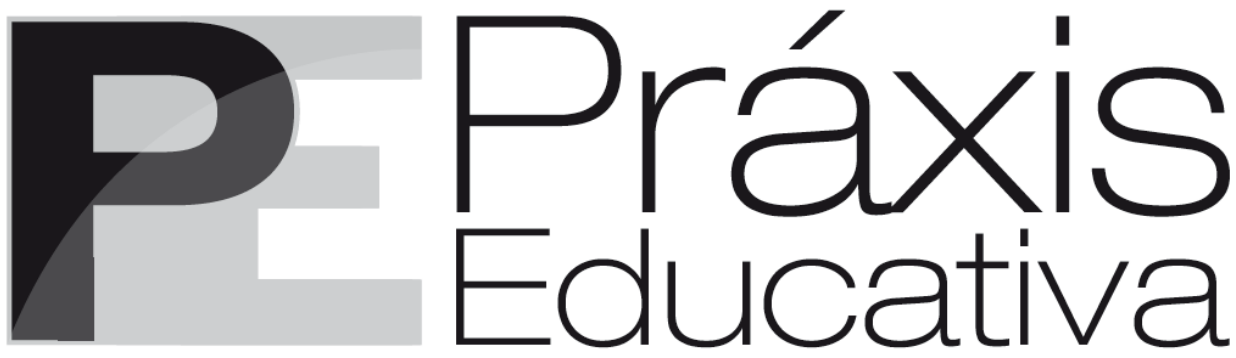

ISSN 1809-4031

elSSN 1809-4309

http://dx.doi.org/10.5212/PraxEduc.v.14n3.023

\title{
Roteiros de coconstrução de conhecimento, expressão e participação: como pessoas jovens (re)criam cidadania?*
}

\section{Routes of construction of knowledge, expression and participation: how do young people (re)create citizenship?}

\section{Rutas de coconstrucción de conocimiento, expresión y participación: ¿cómo personas jóvenes (re)crean ciudadanía?}

\author{
Ana Dias Garcia** \\ Eunice Macedo*** \\ João Queirós ${ }^{* * *}$
}

Resumo: Baseando-se no processo em curso de uma investigação-ação em colaboração com jovens de bairros periféricos da cidade do Porto (Portugal), este artigo apresenta resultados de um conjunto de sessões de cocriação musical e teatral, dinamizadas com dois grupos. Esta pesquisa colaborativa busca refletir e debater o pressuposto que tem prevalecido na sociedade de que os jovens não participam politicamente, bem como procura compreender como é que esses grupos em particular poderão construir a sua cidadania na relação com os seus pares e a sua cidade. São analisados espaços de diálogo, interação social e produção criativa e artística, que sugerem a necessidade destas pessoas jovens se expressarem e serem ouvidas. Considerando as potencialidades emancipatórias do Teatro do Oprimido e da Música, um dos desafios deste estudo é envolver esses jovens como atores e cocriadores na pesquisa sobre a sua realidade e sobre o que os preocupa enquanto jovens cidadãos e cidadãs.

Palavras-chave: Jovens. Cidadania. Investigação Colaborativa.

\footnotetext{
* O presente artigo baseia-se no trabalho em curso de um projeto de investigação desenvolvido no âmbito do Programa Doutoral em Ciências da Educação, na Faculdade de Psicologia e de Ciências da Educação da Universidade do Porto. Este projeto é financiado pela FCT - Fundação para a Ciência e a Tecnologia, através de uma bolsa de doutoramento com a Ref. ${ }^{a}$ SFRH/BD/132196/2017.

** Doutoranda Bolseira de Investigação em Ciências da Educação. CIIE - Centro de Investigação e Intervenção Educativas, Faculdade de Psicologia e de Ciências da Educação da Universidade do Porto. E-mail: anitaldgarcia@gmail.com. ORCID: https://orcid.org/0000-0003-4723-8561

*** Professora Auxiliar e Investigadora. CIIE - Centro de Investigação e Intervenção Educativas, Faculdade de Psicologia e de Ciências da Educação da Universidade do Porto. E-mail: eunice@fpce.up.pt. ORCID: https://orcid.org/0000-0003-1200-6621

**** Professor Adjunto Convidado e Investigador. Escola Superior de Educação do Politécnico do Porto e Instituto de Sociologia da Universidade do Porto. E-mail: jqueiros@letras.up.pt. ORCID: https://orcid.org/0000-0002-35005587
}

Práxis Educativa, Ponta Grossa, v. 14, n. 3, p. 1230-1250, set./dez. 2019 Disponível em: <http://www.revistas2.uepg.br/index.php/praxiseducativa > 


\begin{abstract}
Based on the ongoing process of an action research in collaboration with young people from peripheral neighbourhoods in the city of Porto (Portugal), this article presents the results of a set of sessions of musical and theatre co-creation with two participating groups. The starting point of this collaborative research is to reflect and debate the assumption that young people do not participate politically. We also want to understand how these groups of young people can build their citizenship in the relationship with their peers and their city. Spaces of dialogue, social interaction and creative and artistic production are analysed, suggesting that these young people need to express themselves and be heard. Considering the emancipatory potentialities of the Theatre of the Oppressed and Music, one of the challenges of this study is to engage these young people as actors, co-creators and co-authors in the research about their reality and on issues affect and concern them as young citizens.
\end{abstract}

Keywords: Young People. Citizenship. Collaborative Research.

Resumen: Basándose en un proceso en curso de investigación-acción hecho en colaboración con jóvenes de barrios periféricos de la ciudad de Oporto (Portugal), este artículo presenta los resultados de una serie de sesiones de co-creación musical y teatral com dos grupos. Esta investigación colaborativa busca reflejar y debatir el supuesto que ha prevalecido en la sociedad de que los jóvenes no participan políticamente, así como procura comprender cómo estese grupos de jóvenes podrán construir su ciudadanía en la relación con sus pares y su ciudad. Se analizan espacios de diálogo, interacción social y producción creativa y artística, que sugieren la necesidad de estos jóvenes en expresarse y ser oídos. En vista de las potencialidades emancipatorias del Teatro del Oprimido y de la Música, uno de los desafíos de este estudio es involucrar a estos jóvenes como actores y co-creadores en la investigación sobre su realidad y sobre lo que les preocupa mientras jóvenes ciudadanos y ciudadanas.

Palabras clave: Jóvenes. Ciudadanía. Investigación Colaborativa.

\title{
O ponto de partida
}

O projeto de investigação que desencadeou esta reflexão parte do questionamento crítico sobre o pressuposto de que as pessoas jovens atualmente não são ativas politicamente, não exercem a sua participação cidadã e não revelam interesse por questões públicas comuns. Tem-se em conta que o enfraquecimento dos laços sociais (PAUGAM, 2001) e o refúgio no mundo digital poderão, eventualmente, contribuir para alimentar esta suposição e os argumentos de quem acredita que o suposto fraco empenho político das pessoas jovens poderá ameaçar a democracia e a coesão social (PERLIGER; CANETTI-NISIM; PEDAHZUR, 2006; GALSTON, 2001).

Nesta conjuntura, essa problemática debate-se a partir da conceção de um núcleo de jovens que são desafiados a envolver-se na pesquisa social acerca da sua realidade, na participação e na produção artística, emergindo essa construção em contextos educativos não formais, orientados por processos investigativos participados e colaborativos. Neste grupo de pesquisa com jovens, procura-se compreender como poderão construir a sua cidadania na relação com os seus pares e com a sua cidade, sendo analisados espaços de diálogo, interação social e de produção criativa e artística. Nesta investigação com dois grupos de jovens entre os 13 e os 17 anos, de uma constelação de bairros da cidade do Porto (Portugal), o teatro, a música e outras formas artísticas têm sido propostas enquanto metodologias colaborativas e criativas, das quais têm surgido dados de pesquisa construídos na interação gerada. De modo a promover o diálogo, o pensamento crítico e a expressão criativa, têm sido desenvolvidas atividades em grupo geradoras de contextos diferenciados de aprendizagem e participação. Desses contextos, têm emergido dados que contrariam a tese recorrente segundo a qual as pessoas jovens não se envolvem política e socialmente, sugerindo que, efetivamente, elas se interessam e preocupam com questões sociais e políticas e têm necessidade de intervir e se expressar, de formas diferenciadas, e atuar de

Práxis Educativa, Ponta Grossa, v. 14, n. 3, p. 1230-1250, set./dez. 2019 Disponível em: <http://www.revistas2.uepg.br/index.php/praxiseducativa> 
forma individual ou coletiva por meios não convencionais onde conseguem manifestar-se de uma forma mais fluída e direta (HARRIS; WYN; YOUNES, 2010; NORRIS, 2002).

Nesse sentido, o presente texto convida a uma reflexão sobre a atual ação ou inação política e cidadã das pessoas jovens e sobre o que as afeta e preocupa enquanto cidadãs e cidadãos. Por outro lado, propõe olhar a arte, em particular o teatro e a música, enquanto elementos centrais de processos criativos e reflexivos multidisciplinares. Estes poderão ser um desafio e uma oportunidade para a inclusão e a cooperação entre grupos jovens, nomeadamente no trabalho com grupos em situações socialmente frágeis e de maior vulnerabilidade (MACEDO; CLOUGH; SANTOS, 2017). Este trabalho procura também um cruzamento da relação de jovens entre si e com os seus contextos e as diversas formas de apropriação de recursos, artísticos e/ou digitais, como possibilidades de expressão e de participação.

Considerando que as práticas artísticas constituem uma dimensão estética (DEWEY, 2010), crítica e criativa, e que poderão proporcionar espaços de aprendizagem e expressão, estimular o debate e a construção de formas alternativas de participação social e política (STAHL, 2009), incluir uma abordagem artística e criativa nas metodologias participativas de investigação tem facilitado não apenas o processo de produção de conhecimento, mas também a construção de uma cidadania participativa. Pressupondo um processo composto por experiências coletivas que implicam partilha, escuta, reflexão crítica, interpretação e tomada de consciência da posição de cada pessoa e do grupo, as práticas de investigação participativa permitem a análise e (des)construção permanentes das perceções e conceções individuais e coletivas acerca da organização social (BOAL, 2005). Essas metodologias possibilitam ainda uma observação e um conhecimento mais próximos das diversas trajetórias individuais e coletivas, de processos de socialização, interação e suas múltiplas dinâmicas adjacentes.

Desse modo, e a partir desta abordagem que privilegia processos (auto)reflexivos e cocriativos na construção participada de conhecimento, serão apresentados resultados gerados em um conjunto de sessões com base no Teatro do Oprimido (TO) e na cocriação musical. Sendo estimuladas competências investigativas, o grupo de jovens participa, então, como cocriador e coautor na construção de conhecimento.

Assumindo uma prática dialógica e emancipatória, o TO permite desconstruir e denunciar estruturas de poder, que promovem injustiças, desigualdades sociais e opressão, através de exercícios teatrais que permitem criar condições para que as pessoas se libertem e assumam o papel de produtoras de cultura e de conhecimento. Isso implica o anúncio de outros mundos possíveis, como refere Freire $(2001,1997,1976)$. O TO pressupõe, assim, debate e problematização de questões do quotidiano de modo a formular uma reflexão sobre relações de poder e situações que enquadrem conflitos entre um opressor e um oprimido, as "situações limite de opressão" (FREIRE, 2018; BOAL, 2009). Tomando consciência dessas situações de opressão em um enquadramento dialógico, para, posteriormente, se libertarem delas, as pessoas poderão sentir-se mais capazes de criar, agir e intervir ativamente no seu meio e transformar a sua realidade. Através dessa "libertação consciente e solidária" é possível construir uma sociedade mais democrática e envolvida na participação cidadã (BOAL, 2009, p. 19-20).

Por sua vez, os efeitos positivos da criação musical coletiva refletem-se no modo como esta prática pode disseminar um processo expressivo de partilha e participação, assim como uma experiência reflexiva pautada pela coconstrução de sentidos e representações da realidade. Simultaneamente, a criação musical coletiva poderá ter um papel relevante no desenvolvimento pessoal e social das e dos elementos do grupo, tal como no fortalecimento da cooperação e dos vínculos sociais (HALLAM, 2010), podendo, portanto, constituir um catalisador para a participação cidadã. Será ainda interessante referir que a acessibilidade de vários recursos online de

Práxis Educativa, Ponta Grossa, v. 14, n. 3, p. 1230-1250, set./dez. 2019 Disponível em: <http://www.revistas2.uepg.br/index.php/praxiseducativa > 
produção e divulgação musical tem permitido que as populações mais jovens se apropriem de diversas plataformas de comunicação e participação como meios de expressão, afirmando, deste modo, a sua capacidade de reinventar novas formas de intervenção social e política (GUERRA, 2013).

\section{Cidadanias jovens “em crise”? Que contextos? Que tensões?}

No mundo de hoje, no contexto da globalização, vive-se em permanente e veloz transformação, sendo que esta constante, que nos impele para uma espécie de "ordem global", afeta a vida social e cada ser humano em diversas dimensões. Se, por um lado, este processo presume o progresso da ciência e da tecnologia, e promove a comunicação e a mobilidade de pessoas, por outro, ele envolve um conjunto de riscos, incertezas e desafios sociais e ambientais em nível global (GIDDENS, 2000; CURTO, 2016).

Os riscos sociais e os "efeitos secundários" da sociedade moderna são também referidos, de forma especialmente detalhada, pelo sociólogo Ulrich Beck, que os apresenta como um diagnóstico social e cultural moderno (BECK, 2015). A conceção de "sociedade de risco" é o ponto de partida que Beck (2015) propõe para uma reflexividade sobre as dinâmicas da estrutura da sociedade contemporânea e sobre a possibilidade de agir sobre esse risco e propor mudanças na sociedade. Esse cenário de "riscos" e tensões tem consequências grandes na vida quotidiana (SENNET, 2009), nas dinâmicas dos diversos relacionamentos sociais, na prática democrática e cidadã, como já referia Giddens (2002).

No contexto ocidental atual, entre a diversidade de contextos sociais e culturais e a incapacidade de mitigar as desigualdades e as injustiças sociais (SANTOS, 2005), deparamo-nos com velhos e novos desafios à inclusão e à justiça social. Simultaneamente, tem-se constatado um enfraquecimento das relações comunitárias, dos laços sociais horizontais e da solidariedade (PAUGAM, 2001), processo que, de certa forma, continua a espelhar o perfil de uma sociedade empenhada em valorizar o capital, os interesses comerciais e financeiros, em detrimento dos direitos humanos e valores éticos. Nesta conjuntura, as comunidades poderão ser contextos importantes para o desenvolvimento das relações interpessoais, dos afetos, da solidariedade e da participação. E a população jovem poderá ter um papel relevante na construção desses vínculos e processos interventivos, assim lhes seja dado espaço para que isso aconteça, como argumentamos.

Em uma sociedade em rápido progresso tecnológico, que exige permanente atualização, estruturas tradicionais como a família, a comunidade ou até mesmo os sistemas políticos, poderão tornar-se desajustadas ou desatualizadas em um processo que é de continua renovação e modernização. As próprias formas de construir-se e praticar cidadania e democracia alteraram-se e essa reflexão é especialmente relevante quando olhamos à lupa a população jovem contemporânea. Se, por um lado, existe a perceção de que as pessoas jovens não têm interesse pela política ou pelos políticos, nem pelos modelos tradicionais de participação, como referimos acima, por outro, nas últimas duas décadas, as e os jovens têm vindo a organizar-se em associações, movimentos sociais e plataformas de participação online para manifestar as suas principais preocupações, tais como por exemplo, a ecologia e os direitos humanos, como já referia Giddens, afirmando que a "[...] revolução das comunicações produziu cidadanias mais activas, mais reflexivas, do que as que existiam antes” (GIDDENS, 2000, p. 73).

Ao longo das últimas décadas, atravessando a turbulência de alguns cenários políticos e sociais, a mobilização social deste grupo revelou-se muito expressiva, contrariando a perceção que o discurso adulto dominante avança sobre este tema. Ao longo da segunda metade do século

Práxis Educativa, Ponta Grossa, v. 14, n. 3, p. 1230-1250, set./dez. 2019 Disponível em: <http://www.revistas2.uepg.br/index.php/praxiseducativa $>$ 
XX assistiu-se a momentos acesos de contestação e reivindicação por parte da população jovem, nomeadamente no brotar dos movimentos estudantis das décadas de 1960 e 1970, na Europa, desde logo, mas também em outros pontos do globo. Estas lutas de jovens estudantes que procuravam uma transformação social, e que prosseguiram nas décadas posteriores, associadas também a outras causas como, por exemplo, os movimentos antiguerra, antiglobalização, e, mais recentemente, a greve mundial dos jovens pelo clima, têm ecoado em vários países e revelam a ânsia das pessoas jovens por um mundo melhor, mais justo e menos desigual.

Assumindo diversas formas de ação, como marchas ou manifestações de rua, ocupações de edifícios, pintura de murais, assinatura de petições e, recentemente, manifestações de diversos cariz nas redes sociais e de comunicação online (BRITES, 2015), algumas destas participações juvenis têm sido experiências relevantes de aprendizagem e prática política (DRAGO, 2004; SEIXAS, 2005).

Feitas de conquistas e derrotas, as mobilizações juvenis permitem afirmar que, afinal, nem todas as pessoas jovens estão "adormecidas" e que a sua participação pode estar diretamente ligada não apenas com o que leem e poderão, eventualmente, aprender na escola sobre cidadania, mas, sobretudo, com a experiência e vivência em sociedade e nas relações interpessoais.

Considerando o papel relevante que as e os jovens poderão ter no desenvolvimento das comunidades a que pertencem, revela-se importante analisar se e como este grupo, diverso e composto por uma multiplicidade de trajetórias individuais, poderá interpretar, intervir e traduzir uma realidade social nas suas várias dimensões. Daí a importância de incluir jovens nesta investigação como coprodutores de conhecimento, protagonistas, colaboradores ativos, investigadores, no âmbito de uma pesquisa de aprendizagem, participação crítica e prática democrática.

Porém, neste tempo de experiências e vivências diversas, os conflitos surgem quando, por um lado, a sociedade espera que as e os jovens desempenhem um papel de atrizes/atores e, por outro, que se submetam a um conjunto de normas sociais e padrões morais dominantes (SILVA, 2010). Numa conjuntura diversa de processos transitórios, "experimentando várias tensões, os/as jovens procuram construir biografias" (SILVA, 2010, p. 35) de si próprios, desenhando diversos caminhos e possibilidades, testando e apropriando-se de recursos de expressão e representação das suas múltiplas subjetividades e formas de ver e viver o mundo, nomeadamente as suas relações com os contextos que os envolvem e a construção das suas ações enquanto atores e autores sociais e políticos.

Atualmente, e porventura em outros momentos da nossa história, emerge um lamento nos discursos do senso comum, bem como do mainstream mediático e de alguns setores do campo político, relativo ao desapego das e dos jovens pela participação política e cidadã e pelo envolvimento em questões públicas. A preocupação gerada por esse suposto desinteresse pela intervenção ativa nos assuntos que os rodeiam parece estar associada ao receio da falência da democracia no futuro e ao desenvolvimento de gerações individualistas e indiferentes aos interesses comuns e coletivos (PERLIGER; CANETTI-NISIM; PEDAHZUR, 2006; GALSTON, 2001).

Contudo, e apesar deste olhar descrente relativo à participação das pessoas jovens, reconhecemos que esta se concretiza de novas e diferentes formas que se relacionam não apenas com a diversidade de contextos e recursos como também com a multiplicidade de identidades e culturas juvenis, tal como abordaremos no ponto seguinte.

Práxis Educativa, Ponta Grossa, v. 14, n. 3, p. 1230-1250, set./dez. 2019 Disponível em: <http://www.revistas2.uepg.br/index.php/praxiseducativa> 


\section{Construção de cidadanias e de ação política de jovens: olhares e vozes plurais}

No panorama da sociedade contemporânea, e no quadro do desenvolvimento da reflexão académica acerca das pessoas jovens, é cada vez mais realçada a conceção de juventude enquanto categoria social plural e complexa, que vai para além da análise com base em critérios etários. Alguns estudos têm servido de base para compreender a multiplicidade de identidades e culturas juvenis, permitindo, desse modo, a abertura de caminhos para novas reflexões e aceções no sentido da desconstrução de estereótipos, preconceitos e padrões associados às diversas culturas, práticas e comportamentos juvenis, em um enquadramento de reconhecimento e de valorização da heterogeneidade que carateriza este grupo social $\left(\mathrm{MACEDO}^{1}, 2009,2018\right.$; SILVA, 2010; PAIS, 2003).

Sendo um conceito ideológico, integrado na cultura, no espaço social e no tempo que se desenvolve e se inscreve, geralmente, no período etário entre a infância e a fase adulta, a "juventude é uma categoria socialmente construída, formulada no contexto de particulares circunstâncias económicas, sociais ou políticas" (PAIS, 2003, p. 37). O desenvolvimento dos estudos sobre crianças e jovens nutriu um novo paradigma sociológico, que perceciona estes grupos sociais, constituídos por seres humanos diversos com particularidades, caraterísticas e culturas próprias, como essenciais na construção das comunidades e do seu universo social. À luz destes estudos relativamente recentes, e à semelhança do que defende Mary Bucholtz (2002), consideramos fundamental reconhecer as pessoas jovens enquanto atores sociais e culturais, capazes de construir o seu próprio conhecimento e o seu mundo.

Contrapondo a conceção de que as e os jovens são cidadãs/os em vias de o ser, de que são pessoas ainda a ensaiar aquilo que alguma vez serão, sendo encarados como o futuro e não o presente (PLUMMER, 2003), acreditamos ser indispensável para este debate pensar na necessidade de ampliar os contextos, as formas, as condições e os processos de participação de modo a possibilitar que crianças e jovens, nas suas múltiplas dimensões e na sua diversidade, participem efetivamente como cidadãs e cidadãos no presente (MACEDO, 2009, 2018).

Quando nos referimos à cidadania das pessoas jovens, para além da relevância de incluir este grupo social nos diversos contextos de participação política é, sobretudo, importante considerar e reconhecer a sua diversidade, ter em conta as suas subjetividades, os seus movimentos, as suas expressões, os seus interesses, as suas necessidades e reivindicações.

Ao longo dos últimos anos, muitos discursos académicos e políticos se teceram em torno do conceito de cidadania. Porém, a palavra tem suscitado inúmeras reflexões e inquietações, nomeadamente por representar para algumas pessoas apenas uma parte da sociedade, $\mathrm{O}$ fragmento adulto, "masculino, branco, normal, heterossexual", e excluir os "outros" (LISTER, 2002 , p. 165). Nesta perspetiva, a cidadania tem "funcionado simultaneamente como força de inclusão e exclusão" (LISTER, 2002, p. 166), isto é, inclui a reivindicação de direitos humanos e, ao mesmo tempo, depara-se com situações de marginalização de grupos excluídos, que lutam ainda por uma cidadania prometida, pelo direito à igualdade, mas, simultaneamente, pelo direito a ser diferente (LISTER, 2002). Com isso, poderemos dizer que a cidadania está em permanente (re)construção, no sentido de um ideal mais inclusivo e plural.

\footnotetext{
1 Macedo $(2009,2018)$ recusa o termo 'juventude' pelo seu potencial homogeneizador, substituindo-o por 'pessoas jovens' como reconhecimento da heterogeneidade intragrupal, e em linha com a proposta de Iris Young no que refere ao grupo 'mulheres'.
}

Práxis Educativa, Ponta Grossa, v. 14, n. 3, p. 1230-1250, set./dez. 2019 Disponível em: < http://www.revistas2.uepg.br/index.php/praxiseducativa> 
Neste seguimento, acentuamos que "[...] a cidadania não é apenas um estatuto, em termos de direitos e obrigações, mas constitui também formas de identidade e de reclamação por reconhecimento e justiça social. E expressa também formas plurais de pertença e participação (...)" (MACEDO, 2018, p. 72).

Também a aceção de cidadania com um caráter polifónico, assume a diversidade “[...] como valor nos sentidos de cidadania, significando a inclusão diferenciada de grupos com experiências diferentes entre si, que reclamam a sua própria voz [...], e de grupos que, para se afirmarem em torno da cidadania, têm de saber dialogar entre si na diversidade" (ARAÚJO, 2007, p. 110).

A partir destas interpretações, esta pesquisa argumenta que o exercício da cidadania se faz participando, agindo e interagindo com as e os outras/os e com o meio em um contexto de liberdade e partilha de experiências e de diversas leituras do mundo. À semelhança do princípio do "aprender fazendo", por exemplo, desenvolver a atividade educativa assente no exercício democrático, admitindo que só se alcança a democracia exercitando a democracia (DEWEY, 2007), admitimos que a participação cidadã aprende-se participando.

Deste modo, tem sido analisado um conjunto de práticas criativas e dialógicas de aprendizagem crítica, que garantam que cada jovem participante, além de investigar a sua própria realidade, faça parte da criação de espaços de produção de ações transformadoras na sua comunidade (FREIRE, 1997). A participação de crianças e jovens em eventos sociais e ações políticas, gerando oportunidades para o acesso aos variados recursos e ao exercício da cidadania em condições de igualdade, é a inclusão destas pessoas jovens na comunidade enquanto atores e autores da sua história e trajetória individual e coletiva (GAITÁN; LIEBEL, 2011).

Contudo, sendo para alguns considerada problemática a participação cidadã e política por parte das e dos jovens, por esta não dar resposta efetiva às suas necessidades, interesses, identidades e diversidade (PAIS, 2005), torna-se necessário criar espaços plurais de partilha de experiências educativas alternativas e de expressão livre, onde jovens possam expressar a sua vOz e visibilidade, participando na tomada de decisão e propondo soluções criativas aos problemas que afetam as suas vidas. Reconhecendo e respeitando a diversidade e a heterogeneidade humana, potencia-se a inclusão de novos grupos, enriquecendo, deste modo, as diversas dimensões que compõem a cidadania (MACEDO, 2018). Neste sentido, e contrariando os obstáculos que possam inviabilizar e/ou invisibilizar a participação efetiva da população jovem, "[...] propiciar às pessoas jovens a participação em atividades abertas e sem discriminação, que estimulem o seu contributo para uma sociedade com uma «consciência mais solidária» e para viverem uma «cidadania plena»" (MACEDO, 2018, p. 32), faz parte do desafio europeu de incluir as pessoas jovens na construção do universo social e dar resposta ao seu direito e desejos de expressão.

A abertura de espaços de expressão e participação jovem nos diversos contextos formais e informais da sociedade, para além de poder despertar competências criativas, autogestão, colaboração e de prática democrática, poderá apresentar "o potencial de capacitar os participantes para desempenharem um papel ativo na sociedade e nas suas instituições, constituindo-se num motor para o avanço social e humano, consolidando e enriquecendo a cidadania" (SILVA, 2007, p. 237).

Apesar de alguma desilusão com o modo de funcionamento das instituições e com os modelos tradicionais de participação política, as e os jovens expressam necessidades de 
associação coletiva e de participação cívica (EACEA, 2013)², que destilem as suas identidades, subjetividades e reivindiquem a sua existência e reconhecimento social (HONNETH, 2003). Nestes trajetos de expressão e ação, as pessoas jovens reivindicam, sobretudo, as suas identidades, as suas culturas, os seus estilos e qualidade de vida, o bem-estar pessoal, o seu direito à liberdade individual, à sexualidade, ao corpo e outras questões relacionadas com o género (PAIS, 2005). Durante estes processos, as e os jovens poderão reclamar a sua liberdade, os seus sentimentos de pertença, a importância das relações com os pares e a afirmação da sua diversidade e culturas, sustentando campos onde se constroem enquanto atores sociais e políticos.

Por outro lado, e em algumas perspetivas acerca das vivências de cidadania durante o tempo de ser jovem, são salientadas relações de dependência e de poder desigual entre pessoas adultas e crianças/jovens, no quadro das quais as primeiras prevalecem em uma posição de domínio e controlo - adultocentrismo -, e as visões paternalistas baseadas no conservadorismo cultural e na autoridade parental, que constituem um entrave à participação, à tomada de decisões e à emancipação da população jovem (MACEDO; ARAÚJO, 2012). Nesse cenário, as tensões geradas por estas relações de poder entre gerações poderão colocar algumas pessoas jovens em posição de subordinação, que poderá variar tendo em conta os contextos sociais e culturais em que se encontram.

Admitindo a importância e a influência das dimensões do âmbito demográfico e socioeconómico das e dos jovens - o sexo, a faixa etária, o nível de escolaridade, a situação económica, - e dos seus contextos sociais, tais como o familiar e o grupo de pares, a educação e, portanto, o capital cultural destes, revelam ter um papel fundamental no estímulo da sua participação cidadã (RIBEIRO; NEVES; MENEZES, 2016). Entre um conjunto amplo de contextos de socialização, espera-se da escola a formação de cidadãos e cidadãs, porém esta nem sempre é eficaz no reconhecimento do espaço escolar enquanto cenário de ação cidadã, onde esta seja efetivamente praticada, vivida e articulada com a vida exterior à escola, portanto, com os diversos contextos da vida em sociedade, tal como já alertava Correia (2001).

Tendo em conta dados recolhidos ao longo da presente investigação e os diversos processos de transformações das (sub)culturas jovens das sociedades contemporâneas observadas pelas pesquisas realizadas nesse domínio, é possível acentuar a capacidade das pessoas jovens para reinventar as suas práticas cidadãs e ações políticas (GUERRA, 2013). A perceção de que as pessoas jovens não participam na sociedade é colocada em causa por estudos europeus recentes, que indicam que efetivamente as e os jovens são mais críticas/os do que apáticas/os, utilizam diversas novas formas de participação, nomeadamente "estratégias poéticas e performativas" (RAPOSO, 2015, p. 5) e plataformas digitais multimédia, que facilitam a amplificação das suas vozes (EACEA, 2013). Neste quadro, as e os jovens exploram novos recursos e meios de participação online, tais como o recurso a petições, à produção de vídeos para publicação no Youtube, à criação de páginas temáticas e de grupos de discussão em redes sociais, a protestos de rua e a outras formas criativas de expressão política (EACEA, 2013).

Os processos de construção de conhecimento e de cidadania precisam de espaços abertos de encontro de ideias, diálogos e experiências, de forma a facilitar o trabalho colaborativo e a valorizar as diversas subjetividades. Em sintonia com a reflexão que se propõe neste trabalho, "[...] a importância do pensamento crítico é particularmente decisiva para a boa cidadania numa sociedade" (NUSSBAUM, 2014, p. 77) plural habitada pela diversidade, onde há espaço para maior abertura de pensamento, novas visões, criatividade, questionamento, para existir e resistir,

2 EACEA - Education, Audiovisual and Cultural Executive Agency (European Commission), no âmbito do relatório "Youth Participation in Democratic Life" (fevereiro de 2013).

Práxis Educativa, Ponta Grossa, v. 14, n. 3, p. 1230-1250, set./dez. 2019 Disponível em: <http://www.revistas2.uepg.br/index.php/praxiseducativa $>$ 
podendo haver maior capacitação para o exercício da cidadania. E neste exercício reconhece-se que

\begin{abstract}
Uma pessoa pode tornar-se mais competente, mais capaz, mais complexa na forma como formula opiniões na medida em que se vai confrontando com a realidade. [...] Muito do discurso sobre o problema da cidadania dos jovens, da sua falta de participação [...], não visa resolver qualquer problema, mas visa apenas a manutenção da situação de exclusão dos jovens. (MENEZES, 2014, p. 26).
\end{abstract}

A afirmação e a prática de direitos de cidadania jovem é uma oportunidade para que se apropriem dos vários recursos, de modo a dar vida ao seu protagonismo e voz, criando novas formas de expressão e ação, novas plataformas de intervenção, contribuindo para novas experiências educativas e de intervenção social (MADEIRA, 2013). E é nesta direção que o presente trabalho se inspira e acentua a sua prática e compromisso com os seus participantes, como exploramos na secção seguinte que foca o método.

\title{
Investigação-ação participativa, colaborativa e ativista
}

Durante este percurso investigativo, tem sido proposto um olhar sobre as pessoas jovens a partir da construção e experiência das suas cidadanias e interações coletivas em contextos de ação criativa, participativa e colaborativa. A partir do paradigma sociocrítico e tendo como base uma “"atividade prática', ou, por outras palavras, a ação sobre o mundo [...], que está na base da transformação física do mundo e, consequentemente, de como pensamos" (AMADO, 2017, p. 53), a presente pesquisa tem incidido na coconstrução de um processo dinâmico, participado, transdisciplinar e transformador, que pressupõe reflexão e questionamento permanentes do coletivo.

Tendo como base a linha metodológica da investigação-ação participativa, esta pesquisa com jovens presume o compromisso de estudar/investigar a realidade, refletir sobre ela através de mecanismos de vigilância crítica no âmbito da dimensão artística, valorizando e encarando as e os participantes como protagonistas da ação de um roteiro investigativo transdisciplinar.

A investigação orientada para a ação envolve a geração de possibilidades de mudança, com recurso a métodos e técnicas de pesquisa que permitam a partilha de experiências críticas e criativas, a coordenação e a cooperação entre os atores envolvidos na pesquisa com vista à ação, ilustra um processo que pretende "[...] obter ideias a partir da prática como meio de incrementar o conhecimento acerca dessa prática" (AMADO, 2017, p. 190). Logo, ao longo desse processo dialético entre ação e reflexão, objetividade e subjetividade, “[...] há produção do saber, através da reflexão sobre a ação, proporcionando, assim, um aumento do conhecimento do ou dos pesquisadores e das pessoas consideradas na situação e contexto investigado" (AMADO, 2017, p. 190). Dessa forma, o estudo e a pesquisa enriquecem à medida que se constrói informação e se produz mudança, valorizando sempre a experiência e os contributos de atores sociais comprometidos, neste caso, as vivências, as criações, as propostas e os discursos das e dos jovens.

A opção por esta metodologia relaciona-se com a intenção de mobilizar estratégias que permitam criar espaço para o protagonismo e voz das e dos participantes, para que não se limitem a um papel passivo e estático na investigação, mas, em contraposição, assumam um papel ativo e interventivo. A inclusão das vozes do grupo participante na investigação é uma forma de impulsionar a participação crítica das pessoas envolvidas e incorporar democracia como autorrepresentação, como oportunidade para intervir, propor e agir. Sobretudo grupos de jovens em situação de vulnerabilidade social requerem espaços, recursos e formas de expressão

Práxis Educativa, Ponta Grossa, v. 14, n. 3, p. 1230-1250, set./dez. 2019 Disponível em: <http://www.revistas2.uepg.br/index.php/praxiseducativa> 
participativa, que lhes permitam acrescentar conhecimento, experiência, diálogo, mudança com propósitos emancipatórios (SILVA, 2007).

Tendo em conta a autora Sofia Rosas da Silva, a investigação-ação poderá compor uma dinâmica educativa

[...] ao serviço da promoção da cidadania democrática, na medida em que esta ocorre quando um conjunto de pessoas se envolve, compromete e empenha num esforço concertado de reflexão crítica do mundo e de realização conjunta de uma actividade ou tarefa através de uma solução partilhada. (SILVA, 2007, p. 233).

Portanto, a ação participativa de um grupo poderá acompanhar o desenvolvimento pessoal e de uma comunidade e o desenrolar de processos criativos de rutura com padrões sociais reprodutores de situações de vulnerabilidade, injustiça e exclusão social. O empoderamento dos grupos constitui "um processo de capacitação das pessoas e comunidades" (SILVA, 2007, p. 236), que fortalece o seu direito de participação e de tomada de decisão sobre assuntos relevantes nas suas vidas.

Nesse sentido, a utilização de metodologias participativas, colaborativas, emancipatórias e/ou ativistas (AZAD; FUENTES, 2010) na investigação dá relevo à importância de endereçar os vários desafios e inquietações que emergem da pesquisa e que se prendem com a necessidade de aliar a produção de conhecimento com a transformação social. $O$ desenvolvimento de experiências criativas de aprendizagem não formal a partir de métodos e técnicas artísticas tem materializado, nesta investigação, um processo participado de coprodução de conhecimento, que tem despertado a consciência destas e destes jovens participantes para os direitos humanos, nos quais se incluem a participação cidadã. É, e já Paulo Freire o dizia (FREIRE, 2001, 1997, 1976), no processo de conscientização da realidade e dos seus problemas, que as pessoas compreendem que têm valor e são competentes para desencadear ações capazes de ultrapassar e romper com os problemas que as rodeiam.

Será destacado o trabalho de campo desenvolvido nos últimos quatro meses com dois grupos de jovens com idades entre os 13 e os 17 anos - o grupo A constituído por cinco rapazes e uma jovem mulher e o grupo B, composto por cinco jovens mulheres. Todos os participantes são estudantes do $3 .^{\circ}$ ciclo do ensino básico, que residem em uma zona no limite da cidade do Porto, pontuada por diversos bairros de habitação social e com estabelecimentos escolares integrados no programa "Territórios Educativos de Intervenção Prioritária" étnico racial, os grupos são homogéneos, sendo os respetivos membros naturais da cidade do Porto. O que os dados disponíveis revelam é que uma ampla maioria desses jovens é oriunda de famílias cujos pais e mães ou adultos de referência apresentam ou apresentaram condições socioprofissionais relativas a ocupações operárias ou de emprego de execução nos serviços. Em geral, estamos perante grupos domésticos de extração popular.

Em seguida, apresentamos alguns resultados da pesquisa realizada no contexto de sessões em que foram aplicados exercícios de Teatro do Oprimido (TO) e em que foram incentivadas atividades de cocriação musical com o apoio de recursos colaborativos de produção musical online. Desse modo, os grupos tiveram a oportunidade de se apropriar de práticas e de recursos que lhes permitiram pensar sobre o seu mundo, sonhá-lo, construindo sentidos.

\footnotetext{
3 Trata-se de um programa do governo português implementado no final da década de 1990 do século XX, que pretende prevenir e reduzir o abandono escolar precoce e o absentismo, diminuir a indisciplina e promover o sucesso educativo das e dos estudantes de escolas situadas em territórios socialmente desfavorecidos, afetados pela pobreza e exclusão social.
}

Práxis Educativa, Ponta Grossa, v. 14, n. 3, p. 1230-1250, set./dez. 2019 Disponível em: <http://www.revistas2.uepg.br/index.php/praxiseducativa> 


\section{O Teatro do Oprimido como pesquisa e ação de pessoas jovens}

Neste contexto, afinal que espaços e lugares as pessoas jovens ocupam para construir, dar forma e voz à sua participação cidadã nos dias de hoje? E que processos e resultados se produzirão, propondo uma dimensão estética aos diálogos, às ações, às narrativas e à produção coletiva de conhecimento?

Em uma tentativa de endereçar algumas dessas questões, imergimos no universo do Teatro do Oprimido, das suas possibilidades e potencialidades, enquanto terreno fértil de pesquisa, interação, aprendizagem e criatividade. A importância de (re)inventar a realidade (re)construindo-a coletivamente, "entrando em cena", intervindo, participando e propondo mudanças a favor de interesses comuns, é essencial ao engrandecimento da construção e prática cidadã e ao desenvolvimento das sociedades. Cidadão ou cidadã não é aquele que apenas "vive em sociedade - é aquele que a transforma!” (BOAL, 2009, p. 22).

Neste seguimento, a busca de um método em que as e os jovens sejam participantes ativos, responsáveis pelo seu próprio desenvolvimento e produtoras/es de conhecimento (FREIRE, 1976) está relacionada com a proposta da prática do TO neste trabalho. Por outro lado, enquanto investigadores com experiência na educação com arte, incluindo o teatro, assumimos que o desenvolvimento de técnicas teatrais com jovens pode ser um desafio enriquecedor, porque permite um cruzamento entre descoberta e construção do eu, do coletivo, do mundo, exploração da multiplicidade da realidade, experimentação, reflexão e criação de novas possibilidades. E esse processo imenso e efervescente é uma ampliação dos horizontes do conhecimento.

O Teatro do Oprimido, também enquanto metodologia de investigação, inclui a prática de exercícios expressivos, técnicas e jogos teatrais que visam debate, expressão e problematização de questões do quotidiano com a finalidade de uma reflexão profunda sobre as relações de poder a partir de histórias e situações que enquadrem conflitos entre opressor e oprimido. O âmbito político e pedagógico desta prática está latente na análise da realidade e no processo de conscientização que ele pressupõe.

A par de outras práticas de expressão criativa usadas nesta pesquisa, o TO tem proporcionado aprendizagens e experiências dialógicas que têm focado temas relacionados com as vivências destas pessoas jovens e a forma como veem o mundo, na perspetiva das suas relações sociais e da participação cidadã. Neste sentido, o grupo de jovens propôs um conjunto de tópicos a abordar, afirmando que são questões que lhes tocam particularmente no contexto da escola: desigualdade de género, preconceito e bullying.

A técnica do TO proposta no presente projeto de investigação foi a do Teatro Fórum. Na perspetiva de identificar e analisar através da linguagem simbólica algumas das problemáticas do quotidiano destas e destes jovens, concretizaram-se duas sessões exploratórias de Teatro Fórum, que serão apresentadas no ponto que se segue.

\section{Preconceitos de género: a exclusão das jovens da prática desportiva}

A primeira sessão começou com uma discussão focalizada em grupo de modo a encorajar o grupo a refletir sobre as temáticas apresentadas, expressando de forma descontraída como pensam ou agem sobre esses temas e confrontando ideias. Depois de o grupo se auto-organizar e definir os elementos que atuariam como espetadores participantes e atores que encenam e representam o problema em ação cénica, duas cenas foram apresentadas.

Práxis Educativa, Ponta Grossa, v. 14, n. 3, p. 1230-1250, set./dez. 2019 Disponível em: <http://www.revistas2.uepg.br/index.php/praxiseducativa $>$ 
Num primeiro momento de prática do TO a partir do Teatro Fórum, uma dupla de jovens mulheres abordou a desigualdade de género. As jovens colocaram em cena uma situação com que lidam nas aulas de Educação Física e que as constrange permanentemente: serem excluídas ou desqualificadas nos jogos de futebol em que fazem parte de equipas com rapazes. Para além de terem admitido que estas situações acontecem também em outras modalidades desportivas, as jovens denunciaram que a maioria dos rapazes as anulava nas aulas de desporto, por serem jovens mulheres e as considerarem fisicamente menos competentes para a prática desportiva.

A representação da situação despoletou alguma violência física e verbal por parte da personagem masculina, que procurava impor-se e descredibilizar a feminina. As espetadoras reconheceram imediatamente a situação e manifestaram-se prontamente evocando momentos em que elas próprias sentiram ou assistiram a essa repressão por parte dos rapazes. Visualizando a cena representada, a questão torna-se mais viva e intensa e o grupo expressou-se energicamente a seu propósito. São as posturas, os movimentos, as intenções, os olhares, as respirações, as emoções, as palavras que constituem toda a composição cénica, que exaltam o tema, que dão força à interação e à relação entre o grupo e despertam o pensamento. É essa dimensão libertadora e multidisciplinar do teatro que possibilita um aprimoramento da prática investigativa e educativa.

\section{Bullying homofóbico: uma violência silenciosa}

Noutro momento, um grupo de rapazes apresentou uma cena de violência psicológica entre dois rapazes, mais uma vez na escola, sendo que uma personagem representava uma vítima homossexual. Embora tenha sido referido que a maior parte desse tipo de violência acontece de forma encoberta ou silenciosa, quando as situações ocorrem na presença de docentes ou funcionários da escola estes não intervêm ou mostram não saber como atuar. Tal como apresentado, a fragilidade das vítimas nestas situações dá mais poder aos agressores, piorando a experiência de opressão.

A representação da cena de bullying transportou para o debate outros casos para além da violência homofóbica. O grupo falou de situações de assédio sexual, referiu novamente a violência de género, o racismo e a discriminação por simplesmente se ser diferente seja qual for a razão. O diálogo subsequente à representação da cena é tão rico, que o espaço e o tempo se tornam curtos para a quantidade de histórias, experiências e pensamentos tecidos e partilhados. As diversas análises tecidas pelas e pelos elementos do grupo têm permitido compreender a quantidade de desafios que estas e estes jovens em particular têm de enfrentar, sobretudo na escola, para se integrarem, construírem as suas identidades, as suas culturas, os seus vínculos sociais e a forma como vivem e agem no mundo.

Do ponto de vista ético, quando se tratam e expõem temas sensíveis como são a violência de género, o preconceito ou o bullying nas suas diversas formas, garantir que essas práticas investigativas sejam responsáveis, rigorosas e éticas é fundamental. Respeitar e cumprir um conjunto de valores que salvaguardem uma postura ética em todo o processo de pesquisa e protejam os seus intervenientes é essencial, nomeadamente para proteger as pessoas jovens relativamente à potencial exposição da sua intimidade no seio do grupo, reconhecer e valorizar a sua diversidade, respeitando a autodeterminação e a dignidade de cada pessoa.

Entre outros métodos que têm sido propostos ao grupo no percurso desta pesquisa, o TO tem sido uma estratégia interessante no que diz respeito à criação de coesão entre o grupo, à comunicação, à leitura e reflexão crítica do mundo, ao estímulo de competências criativas e

Práxis Educativa, Ponta Grossa, v. 14, n. 3, p. 1230-1250, set./dez. 2019 Disponível em: <http://www.revistas2.uepg.br/index.php/praxiseducativa> 
expressivas, e à participação nas "políticas do quotidiano". Simultaneamente, ao desenvolver capacidades cognitivas, afetivas, sensoriais e estéticas, tem se observado que esta prática tem, de certa forma, aguçado sensibilidades para a pesquisa, despertando nas e nos jovens curiosidade para maior conhecimento sobre si, sobre aqueles que os rodeiam e a sociedade.

\section{A emergência da produção de vozes jovens: uma experiência de cocriação musical}

Para além do desenvolvimento das aprendizagens anteriormente referidas, a experiência musical em contexto coletivo de cocriação poderá potenciar a autoconfiança, as relações sociais, a cooperação, o sentimento de pertença e de autorrealização (HALLAM, 2010). A música poderá ter não apenas um papel de "afirmação social, mas também potencial para promover o desenvolvimento individual, a renovação cultural, a evolução cultural, a mudança" (SWANWICK, 2003, p. 40). Ao assumir-se como linguagem munida de múltiplas possibilidades criativas e expressivas capazes de traduzir emoções, sensações, desejos e pensamentos, a "[...] música é uma forma de pensamento, de conhecimento. Como uma forma simbólica ela cria um espaço onde novos insights tornam-se possíveis" (SWANWICK, 2003, p. 38). Desse modo, poderá ser um campo favorável para a construção de sentidos e significados, e representações novas da realidade.

Neste seguimento, e no contexto desta investigação, as e os jovens participantes foram desafiadas/os a dinamizar rodas de diálogo e outras atividades coletivas, que pretendiam descortinar, mais uma vez, os assuntos e as temáticas que mais os preocupam enquanto jovens cidadãs e cidadãos. Desigualdades de género, preconceito e injustiças sociais foram os tópicos mais destacados por ambos os grupos, que serviram de mote para a discussão e a criação coletiva de duas letras / poemas. Para além de um processo expressivo, de partilha e participação, esta experiência permitiu a prática reflexiva, interativa, coconstrutora de sentidos e representações das experiências e vivências destas e destes jovens.

Com recurso a duas plataformas gratuitas e colaborativas de composição musical online o Soundtrap e o Incredibox - cada grupo de jovens desenvolveu entusiasticamente uma paisagem sonora para acompanhar as palavras escritas e ditas por cada elemento dos grupos. Com traços da estética Rap, as duas músicas que resultaram destas experiências refletiram perceções e posturas destas e destes jovens relativas à realidade que os rodeia e à necessidade de as expressar e concretizar.

\section{Entre machismo e preconceito: vozes de resistência}

O grupo B, composto pelas cinco jovens, entregou-se a este desafio musical com o entusiasmo de uma primeira experiência. A atividade decorreu numa sala que a escola cedeu para desenvolvermos os trabalhos de pesquisa.

Perante as primeiras conversas informais, este grupo enfatizou as questões de género, à semelhança do que aconteceu no exercício do Teatro do Oprimido. A letra, criada por duas das jovens do grupo, revela preocupações relacionadas, mais uma vez, com a sua posição de desvantagem, num contexto onde, dizem elas, a maioria dos rapazes gosta de se impor. Por outro lado, utilizaram algumas vezes a palavra machismo e relacionaram-no com a violência doméstica e de género, provavelmente também influenciadas pela atual cobertura mediática desse tipo de casos de violência e pelo debate público dessa questão. Porém, e apesar disso, duas das jovens admitiram confrontar-se com situações de violência familiar no contexto dos seus Bairros, facto 
que, uma delas, assumiu como habitual, dizendo - "às vezes bá porrada lá no Bairro, mas en não tenho medo, já estou babituada...".

Outro assunto abordado por esse grupo foi o preconceito associado à diversidade sexual. As participantes referiram já ter assistido, pelo menos uma vez, a ofensas a pessoas que revelam, de alguma forma, a rutura com a heteronormatividade. Nesse contexto, expressaram determinadamente a sua posição de repúdio por quem discrimina ou tem algum tipo de preconceito relativamente à liberdade sexual. O grupo apresentou ainda a necessidade de se falar mais abertamente desta questão em contexto escolar e de mais apoio "para quem tem de lidar com situaçoes de discriminação e, muitas vez̧es, não tem com quem conversar".

Assim, a letra criada refletiu e sintetizou os pontos abordados pelo grupo ao longo da interação que antecedeu o início do exercício. Embora algumas das jovens defendessem que se deveria começar pela composição da música, acabou por se concordar que antecipar a letra seria fulcral para a criação da ambiência sonora certa e consonante com o conteúdo escrito.

Desse modo, entre as duas letristas, o trabalho de cocriação estimulou a discussão crítica e criativa coletiva, que resultou na seguinte letra:

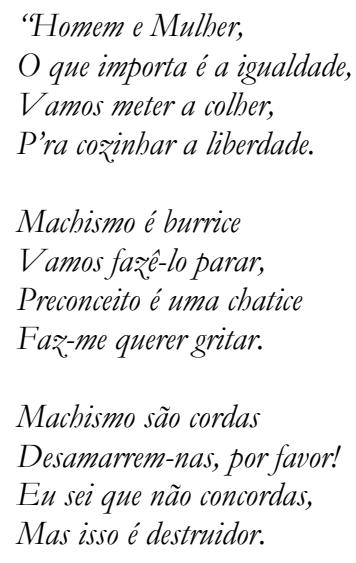

\section{Machismo são cordas \\ Desamarrem-nas, por favor! \\ Eu sei que não concordas, \\ Mas isso é destruidor.}

Preto ou branco, não importa a cor

Há que ser franco e praticar o amor

$V$ amos ter respeito,

E acabar com o preconceito.

\section{Bissexual ou homossexual \\ Não tem nada de mal, \\ Praticas homofobia? \\ Aprende com esta melodia."}

Após a finalização da letra/poema, o restante do grupo já estava à procura de possibilidades sonoras para abraçar as palavras ditas. Com recurso à plataforma online colaborativa de criação musical Soundtrap, o grupo teve acesso a uma biblioteca de sons de diversos instrumentos musicais e loops, que lhe permitiu ouvir, escolher e compor um alinhamento de ritmos e melodias. Simultaneamente, a plataforma Soundtrap, além de permitir gravar sons, nomeadamente vozes para incluir no alinhamento da música, também possibilita o trabalho colaborativo, uma vez que consegue integrar no mesmo projeto musical o contributo de várias pessoas, ainda que estejam em lugares diferentes. Embora esta plataforma permitisse que a composição da música fosse desenvolvida em diversos momentos e com a colaboração de cada elemento do grupo online, as meninas privilegiaram os encontros presenciais para a realização conjunta do trabalho. 
Mais importante do que o resultado, foi o processo que se desenvolveu ao longo da criação coletiva da música. No final, o sentimento de autorrealização sentiu-se entre o grupo na forma como este se mostrou disponível para a criação posterior de um videoclip em que fosse possível retratar visualmente algumas das questões referidas na letra da música, inclusive por meio da criação de uma coreografia coletiva.

\section{"Grito sem voz": transgredir para se fazer ouvir}

O debate e a criação coletiva foram mais longos e densos no grupo A, descortinando-se algumas divergências. Mais revolto e barulhento, este grupo é bastante interveniente e ativo na discussão, apresentando uma visão crítica da realidade existente e algumas perceções de injustiças sociais provenientes das próprias vivências diárias. Composto por elementos que se tocam e se distanciam em diversos pontos, nomeadamente em aspetos relacionados com o contexto familiar, as condições socioeconómicas e a construção identitária, este grupo foi constituindo-se de forma espontânea na medida em que umas e uns iam chamando outras e outros para participar na pesquisa.

Sendo, neste caso, as atividades de investigação realizadas no centro comunitário de um dos Bairros da zona, o distanciamento do espaço escolar formal permitiu criar outro tipo de dinâmicas que possibilitaram libertar mais o grupo. Entre a sala do centro e os espaços comuns do Bairro a distância é pequena, por isso o palco social onde o grupo atua está mais próximo, permitindo observar mais de perto as suas interações.

O debate coletivo acabou por incidir nas experiências individuais que, em certos pontos, traduziram também experiências coletivas. As injustiças sociais referidas pelo grupo relacionamse sobretudo com a perceção de que "a vida é difícil", pois, por mais que os familiares trabalhem, há sempre a sensação de que o rendimento e a segurança não são suficientes, gerando uma situação de permanente desvantagem face aos grupos mais abastados. Este tema surgiu algumas vezes, tendo, inclusive, criado a oportunidade para um dos rapazes do grupo partilhar a sua vontade de trabalhar para ajudar a família, e a sua indignação pela lei não lhe permitir fazê-lo por ser menor de idade.

O questionamento da lei foi e é outro tema que costuma surgir com alguma intensidade, aliado ao desejo de transgressão. A perceção de que "as leis favorecem os ricos" e que os "mais jovens quase nunca são ouvidos" ou considerados em situações que os envolve, justifica em parte a necessidade de alguns elementos do grupo em transgredir, pois sentem que essa "é uma forma de chamarem a atenção e serem ouvidos".

O desejo de expressão acompanhou o sentimento de indignação e injustiça face a uma realidade montada pela "ignorância dos adultos que acham que as crianças não sabem nada sobre a vida...", segundo palavras de um dos rapazes. Nessa sequência, o "Grito sem Voz" surgiu de um poema que a única jovem deste grupo partilhou numa sessão em que se falou da injustiça de mundo em que "só os adultos querem governar". A partir do poema foram se juntando frases mais reveladoras da necessidade de estas pessoas jovens se fazerem ouvir:

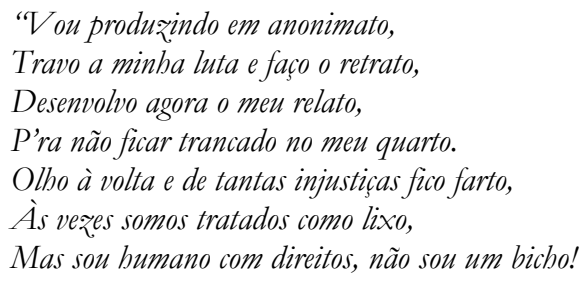

Práxis Educativa, Ponta Grossa, v. 14, n. 3, p. 1230-1250, set./dez. 2019 Disponível em: <http://www.revistas2.uepg.br/index.php/praxiseducativa> 


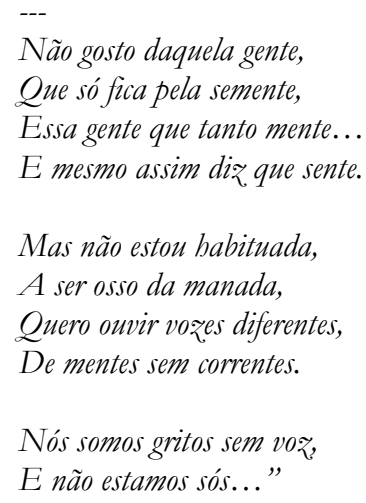

No seguimento da construção da letra/poema, a ideia de que o grupo se sente, de alguma forma, invisibilizado e silenciado ou recluso de uma realidade social caraterizada por injustiças, confronta-se com a união, o companheirismo e a força que encontram no grupo de amigas e amigos e que mostram ser um pilar fundamental nas suas vidas, na forma como se veem, se sentem, constroem as suas identidades e relações com o mundo. Ainda que apresentem algum sentimento de desencantamento com a realidade social, a amizade, a lealdade, as vivências partilhadas no grupo de pares e o sentimento de pertença, que alimentam no grupo são alguns dos elementos-chave para a construção não só da identidade, mas do posicionamento e da ação destas e destes jovens na sua comunidade.

Torna-se claro que laços sociais mais fortes geram mais possibilidades de maior envolvimento e mobilização coletiva, uma vez que as pessoas consideram as redes sociais estruturas mais próximas e fiáveis no que concerne à partilha de informações e debate sobre questões comuns (IGLIC; FÁBREGAS, 2007). São também contextos onde o coletivo cultiva laços de solidariedade, cooperação e coesão, que favorecem a participação e a ação coletiva.

No que concerne à composição da música que deu abrigo à letra construída, esta foi, em primeiro lugar, desenvolvida no Soundtrap, à semelhança do grupo B; no entanto, a divergência de preferências estéticas e a procura de algo diferente levou à pesquisa de programas semelhantes, mas com a possibilidade de terem incorporadas vozes de coro já gravadas. Dessa forma, começaram a trabalhar o áudio na plataforma online gratuita Incredibox. Mais simples e com uma dimensão mais lúdica e intuitiva, a Incredibox possibilitou criar uma mistura de beats e sons vocais em uma sequência rítmica eletrónica não linear.

A experiência empolgou o grupo e a proposta de realizar um videoclip da música para materializar visualmente os temas abordados poderá ser uma oportunidade para este coletivo se afirmar enquanto produtor cultural e emergir criativa e socialmente na interseção das várias subjetividades. A ideia do grupo é produzir o videoclip, criar um website e usar o Youtube como forma de divulgação das suas produções.

Em ambos os grupos, essa experiência de cocriação musical foi importante não apenas para fomentar competências comunicativas, criativas, expressivas e tecnológicas, como também para viabilizar a escuta, o reconhecimento e a inclusão da diversidade de vozes que incorpora a conceção da 'cidadania polifónica', que defende o reconhecimento e legitimação da expressão das diversas vozes, que compõem a heterogeneidade da realidade social (ARAÚJO, 2007).

Realçando a importância da escuta e do reconhecimento da voz das e dos jovens no processo de expressão e ação, no quadro de práticas democráticas e cidadãs, situamos a voz, então, "[...] como símbolo da luta social por reconhecimento e como instrumento para a participação e ação transformativa, uma construção heterogénea informada pelas experiências 
individuais" (MACEDO, 2018, p. 111). Portanto, do mesmo modo que a afirmação da voz poderá ser a possibilidade de cidadania, a escuta, a expressão e a consideração dessa voz poderá ser realização de cidadania (MACEDO, 2018).

\section{Considerações finais}

Parece-nos importante relevar uma perspetiva crítica e mais aberta relativamente aos novos contextos e formas de participação cidadã e política das pessoas jovens, à luz dos diversos desafios, possibilidades e transformações constantes que compõem as sociedades atuais. Entendemos que esta participação poderá ser mais ou menos ativa e empenhada quanto mais ou menos - as e os jovens tiveram oportunidade de alimentar e fortalecer os seus laços sociais, na medida em que estes poderão compor núcleos sólidos de ligações, espaços de comunicação, partilha de informação e discussão acerca de assuntos de interesse comum em diversos contextos sociais informais (IGLIC; FÁBREGAS, 2007). A relação com a realidade, as vivências e experiências quotidianas, o confronto com os diversos desafios e adversidades fazem parte da base para a construção de olhares sobre o mundo, de posicionamentos, opiniões, atitudes e ações, que poderão materializar-se das mais diversas formas, sejam elas através de manifestações de rua, da assinatura de petições ou da criação de músicas e vídeos para divulgação online. As plataformas digitais têm se afirmado como um novo campo de batalha, que tem possibilitado novas formas de produção, comunicação e disseminação criativa e artística. Nesta pesquisa, a internet tem se revelado um dos espaços de expressão e ação do ativismo jovem.

No presente estudo, a partir de uma perspetiva plural e multidisciplinar, a incorporação da prática do Teatro do Oprimido (TO) e da cocriação musical em uma investigação-ação participativa com jovens dá força à construção de um retrato e de uma narrativa social, baseados na interseção das subjetividades jovens, das suas experiências sociais na escola e na comunidade, na suas expressões, diversidades e criatividades. A escola e a paisagem urbana enquanto campos de pesquisa, reflexão, participação e produção coletiva, têm sido cenários para o desenvolvimento em coautoria de um conjunto de práticas experimentais criativas produtoras de conhecimento social, que têm confirmado o desejo destas e destes jovens de se expressar, de serem vistos e ouvidos, de serem tidos em conta na criação de propostas e nos processos de decisão.

As propostas metodológicas apresentadas constituíram um conjunto de experiências exploratórias e emancipatórias, que foram sendo apropriadas e moldadas pelos grupos, na procura de outras leituras e interpretações da realidade. Proporcionando a construção de experiências de aprendizagem crítica e criativa, nomeadamente a de explorarem diferentes olhares e reflexões acerca da sua comunidade e ensaiarem eventuais soluções para alguns dos seus problemas, o TO e o exercício de criação musical coletiva serviram também de ponte entre estes grupos e o universo da investigação social.

Porém, estas pessoas jovens continuam a confrontar-se com barreiras na participação cidadã - incluindo a política - que estão ligadas a constrangimentos e tensões que foram identificadas em contextos como a escola, que deveria também assumir um papel crucial na construção da cidadania das pessoas jovens. Neste cenário, as e "[...] os jovens são expostos ao discurso de que são irresponsáveis, de que não se interessam e de que não querem participar" (MENEZES, 2014, p. 28), sustentando a ideia de que são incompetentes ou imaturos para o fazer. O discurso de que as pessoas jovens são cidadãs em vias de o ser ainda prevalece, mas tem de continuar a ser contestado, reconhecendo-se que, efetivamente, as pessoas jovens são competentes e capazes de fazer leituras críticas sobre a sua realidade, tomar posições e propor mudanças.

Práxis Educativa, Ponta Grossa, v. 14, n. 3, p. 1230-1250, set./dez. 2019 Disponível em: <http://www.revistas2.uepg.br/index.php/praxiseducativa $>$ 
Desse modo, à falta de lugares de estímulo à participação, as e os jovens têm procurado outros espaços de reconhecimento. A importância de incluir as vozes das e dos jovens na investigação, reconhecendo e valorizando a sua diversidade e validade (MACEDO, 2018), é afirmar o quanto estas vozes poderão contribuir para o enriquecimento do conhecimento e do desenvolvimento social.

Potenciada também pelos processos desencadeados pelo tipo de práticas criativas, expressivas e participadas exploradas, a pesquisa em curso tem beneficiado da preciosa contribuição e colaboração de cada jovem. Os recursos inspiradores das linguagens artísticas têm sido orientados pela construção de um processo de escuta, diálogo e de uma consciência crítica da realidade em redor destas e destes jovens em mudança.

\section{Referências}

AMADO, J. Manual de investigação qualitativa em educação. Coimbra: Imprensa da Universidade de Coimbra, 2017.

ARAÚJO, H. C. Cidadania na sua polifonia: debates nos estudos de educação feministas. Educação, Sociedade \& Culturas, Porto, n. 25, p. 83-116, 2007.

AZAD, S.; FUENTES, E. Introduction: activist scholarship - possibilities and constraints of participatory action research. Social Justice, v. 36, n. 4, p. 1-5, 2010.

BECK, U. A Sociedade de Risco Mundial - em busca da segurança perdida. Lisboa: Edições 70, 2015.

BOAL, A. Teatro do oprimido e outras poéticas políticas. Rio de Janeiro: Editora Record, 2005.

BOAL, A. A estética do oprimido. Rio de Janeiro: Garamond, 2009.

BRITES, M. J. Jovens e culturas cívicas: por entre formas de consumo notícioso e participação. Covilhã: Livros Labcom, 2015.

BUCHOLTZ, M. Youth and cultural practice. Annual Review of Anthropology, v. 31, n. 1, p. 525 -552, out. 2002. DOI: https://doi.org/10.1146/annurev.anthro.31.040402.085443

CORREIA, A. A construção científica do político em educação. Educação, Sociedade \& Culturas, Porto, n. 15, p. 19-43, 2001.

CURTO, D. R. Estudos sobre a Globalização. Lisboa: Edições 70, 2016.

DEWEY, J. Democracia e educação. Tradução de Susana Guimarães. Lisboa: Didática Editora, 2007.

DEWEY, J. A arte como experiência. Tradução de Vera Ribeiro. São Paulo: Martins Fontes, 2010. 
Roteiros de coconstrução de conhecimento, expressão e participação...

DRAGO, A. Agitar antes de ousar: o movimento estudantil 'antipropinas'. Porto: Afrontamento, 2004.

EACEA. Education, Audiovisual and Cultural Executive Agency. Youth participation in democratic life. London: EACEA, 2013.

FREIRE, P. Educação como prática da liberdade. 5. ed. Rio de Janeiro: Paz e Terra, 1976.

FREIRE, P. Política e educação: ensaios. 5. ed. São Paulo: Cortez, 1997.

FREIRE, P. Educação e mudança. 12. ed. São Paulo: Paz e Terra, 2001.

FREIRE, P. Pedagogia do oprimido. 3. ed. Porto: Afrontamento, 2018.

GAITÁN, L.; LIEBEL, M. Ciudadanía y derechos de participación de los niños. Madrid: Univ. Pontificia de Comillas Ed. Síntesis, 2011.

GALSTON, W. Political knowledge, political engagement, and civic education. Annual Review of Political Science, v. 4, n. 1, p. 217-234, jun. 2001. DOI: https://doi.org/10.1146/annurev.polisci.4.1.217

GIDDENS, A. O mundo na era da globalização. Tradução de Saul Barata. Lisboa: Editorial Presença, 2000.

GIDDENS, A. Modernidade e identidade. Rio de Janeiro: Jorge Zahar, 2002.

GUERRA, P. A instável leveza do rock: génese, dinâmica e consolidação do rock alternativo em Portugal. Porto: Afrontamento, 2013.

HALLAM, S. The power of music: Its impact on the intellectual, social development of children and young people. International Journal of Music Education, v. 28, n.3, p. 269-289, ago. 2010. DOI: https://doi.org/10.1177\%2F0255761410370658

HARRIS, A.; WYN, J.; YOUNES, S. Beyond apathetic or activist youth: 'Ordinary' young people and contemporary forms of participation. Young, v. 18, n. 1, p. 9-32, fev. 2010. DOI: https://doi.org/10.1177\%2F110330880901800103

HONNETH, A. Luta por reconhecimento: a gramática moral dos conflitos sociais. Tradução de Luiz Repa. São Paulo: Editora 34, 2003.

IGLIC, H.; FÁBREGAS, J. F. Social networks. In: DETH, J. W. V.; MONTERO, J. R.; WESTHOLM, A. Citizenship and involvement in European democracies. New York: Routledge, 2007. p. 188-218.

LISTER, R. Cidadania: um desafio e uma oportunidade para as feministas. Ex-æquo, Lisboa, n. 7, p. 165-178, 2002.

MACEDO, E. Vozes jovens entre experiência e desejo: cidadania educacional e outras construções. Porto: Afrontamento, 2018. 
MACEDO, E. Cidadania em confronto: Educação de jovens elites em tempo de globalização. Porto: CIIE \& Livpsic, 2009.

MACEDO, E.; ARAÚJO, H. C. Jovens em Portugal discutem educação e os rankings das escolas. Organizações e Democracia, v. 13, n. 2, p. 57-72, jul./dez. 2012.

MACEDO, E.; CLOUGH, N.; SANTOS, S. A. Engaging vulnerable young people in education through the arts - Challenges and opportunities. Educação, Sociedade \& Culturas, Porto, n. 50, p. 7-14, 2017.

MADEIRA, R. A participação das crianças na esfera pública: a desigualdade social como desafio. Rediteia - Bem-Estar Infantil - Revista de Política Social, Porto, n. 46, p. 147-165, 2013.

MENEZES, I. Fazer política por outros meios?. In: MACEDO, E. (Org.). Fazer educação, fazer política: linguagem, resistência e ação. Porto: Legis Editora, 2014. p. 19-36.

NORRIS, P. Democratic Phoenix: reinventing political activism. Cambridge: Cambridge University Press, 2002.

NUSSBAUM, M. Educação e justiça social. Mangualde: Edições Pedago, 2014.

PAIS, J. M. Culturas juvenis. Lisboa: Imprensa Nacional - Casa da Moeda, 2003.

PAIS, J. M. Jovens e cidadania. Sociologia, Problemas e Práticas, Lisboa, n. 49, p. 53-70, set. 2005.

PAUGAM, S. O enfraquecimento e ruptura dos vínculos sociais. In: SAWAIA, B. As artimanhas da exclusão: análise psicossocial e ética da desigualdade social. 2. ed. Petrópolis: Vozes, 2001. p. 67-86.

PERLIGER, A.; CANETTI-NISIM, D.; PEDAHZUR, A. Democratic attitudes Among HighSchool Pupils: the role played by perceptions of class climate. School Effectiveness and School Improvement, v. 17, n. 1, p. 119-140, 2006. DOI: https://doi.org/10.1080/09243450500405217

PLUMMER, K. Intimate citizenship: private decisions and public dialogues. Seattle: University of Washington Press, 2003.

RAPOSO, P. "Artivismo": articulando dissidências, criando insurgências. Cadernos de Antropologia a Arte, Salvador, v. 4, n. 2, p. 3-12, 2015.

RIBEIRO, N.; NEVES, T.; MENEZES, I. Participação cívica e política de jovens imigrantes e portugueses. Análise Social, Lisboa, v. 51, n. 221, p. 822-849, out./dez. 2016.

SANTOS, B. S. O Fórum Social Mundial. Porto: Afrontamento, 2005.

SEIXAS, A. M. Aprender a democracia: jovens e protesto no ensino secundário em Portugal. Revista Crítica de Ciências Sociais, Coimbra, v. 72, n. 3, p. 187-209, out. 2005. DOI: https://doi.org/10.4000/rccs.988 
SENNET, R. A corrosão do caráter: consequências pessoais do trabalho no novo capitalismo. São Paulo: Record, 2009.

SILVA, S. L. R. O caminho é a cidadania: investigação-ação, contributos de uma dinâmica educativa. In: RAMOS, F. S. (Org.). Educação para a cidadania europeia com as artes. Coimbra: Grupo de Investigación HUM-742 D.E.Di.C.A. - Desarrollo Educativo de las Didácticas en la Comunidad Andaluza; Universidad de Granada; Center for Intercultural Music Arts, 2007. p. 231-239.

SILVA, S. M. D. Da Casa da Juventude aos confins do mundo: etnografia de fragilidades, medos e estratégias juvenis. Porto: Afontamento, 2010.

STAHL, J. Street Art. [S.l.]: H. F. Ullmann, 2009.

SWANWICK, K. Ensinando música musicalmente. São Paulo: Moderna, 2003.

Recebido em 30/03/2019

Versão corrigida recebida em 28/07/2019

Aceito em 30/07/2019

Publicado online em 07/08/2019 